diameter, formed terminally on aerial conidiophores which may, by repeated growth, bear several conidia. Zygospores were not observed.

Further details of these and other related fungi will be the subject of a paper to be published later.

I should like to express my thanks to Dr. B. Barnes for much valuable advice and help, and also to Dr. C. G. C. Chesters, of the University of Birmingham, for kindly allowing me to use his laboratory.

Department of Biology,

Chelsea Polytechnic,

London, S.W.3.

Jan. 4.

${ }^{1}$ Drechsler, C., Mycologia 27, 6-40; 176-203; 206-215 (1935).

${ }_{2}^{2}$ Penard, E., Arch. Protistenk., 28, 78-140 (1912-13).

\section{Radium Treatment}

Reference is made in Nature of Cecember 9, 1939 , p. 973 , to a paper (J. Roy. Soc. Arts, Dec. 8, 1939) entitled "The Penetration of Rays through the Skin, and Radiant Energy for the Treatment of Wounds", in which I express the view that we would be little the worse off if all the radium now buried in deep holes for security from bombing remained there, and states that the Cancer Act is Great Britain's reply to the question whether monetary influence determines the practice of radium therapy in Great Britain.

Radium, a destroyer of living cells in active division, cannot be used to attack cancer without also damaging living normal cells of the circulating blood, etc. It can only be used for accessible cancers in the skin or surfaces of the body, which can be removed in nearly all cases by the knife or the diathermy needle of the surgeon; and these last do not cause necrosis and incurable neuralgias, which have often followed the use of radium. Deaths due to leucopænia have resulted from vain attempts to cure deep cancers by the use of radium in bombs. I can instance the damage done by radium by a case now attending the St. John Clinic and Institute of Physical Medicine ; radium treatment of a small epithelioma in the skin on the side of the skull resulted in necrosis of the bone, probably incurable, in an area the size of the top of a sherry glass.

Loss of well-being and an incurable neuralgia were recorded by Mr. Furnival, the late distinguished surgeon, who died not long after radium treatment, in his case of cancer of the throat. Such an intolerable neuralgia was suffered by a relative of mine through treatment of a cancer of the root of the tongue, and he also died of a recurrence; and I have heard of many other such cases. There are good clinicians who hold the view that the use of radium favours the spread of metastases. Radium is popular because it can be used instead of the knife, which people dread, and therefore doctors use it.

$X$-ray apparatus is now available which operates at a million volts or more, so that radiations approaching those of radium are produced. The dosage of radium is controlled by time and filtration; that of $\mathrm{X}$-rays can be further controlled in wave-length and intensity. Radium may be chosen as more convenient for application in such a place as the larynx.

Both radium and $\mathrm{X}$-rays can produce, not only necrosis, but also cancer, and Sir Norman Walker considers that the use of X-rays for lupus should be abandoned. I know of an excellent laboratory servant who, only by continued observation and treatment, is kept, so far, free from cancer resulting from scars due to X-ray treatment of lupus of the face.

We know that death has resulted in several workers who licked the paint off brushes when applying luminous, radioactive paint to watch dials, and cancer has resulted from a radium tube being left in the body. Those who mine radium-bearing ore die generally from eancer of the lung.

The Lancet (Dec. 23, 1939) says, "to ensure that radiation treatment is in charge of really competent workers, and to give opportunities for training therapists, a high degree of centralisation will be more effective than the creation of individual treatments units". "To use both radium and X-rays to the best advantage some surgical training and a good grasp of radiation physics are needed, and for the purpose of the Act clinical knowledge of cancer in all its manifestations as well".

While vast sums have been spent on radium, numbers of poor people have to die, unrelieved, of eancer, in their homes. The pressing needs are to spread knowledge, secure prevention where possible, and very early diagnosis, allowing a hopeful removal by the knife or diathermy needle, which can be used by surgeons everywhere, the use of radium or X-rays being reserved for one or two places in the body where surgical operation is very difficult, and to be used by specialists as the Lancet suggests. There is no trustworthy evidence that radium in weak doses has any beneficial action.

St. John Clinic and Institute of Physical Medicine,

Ranelagh Road, London, S.W.1. Jan. 5.

\section{" Evidence for Transformation of Mesotrons into Electrons"}

IN our note under this title published in NATURE of January $20, p .102$, we stated in reference to the cloud photographs reproduced that the faint electron track $F G$, leaving the end of the mesotron track "is comparable in density with the tracks of other fast particles" in the photograph. "This was the case in the original negatives, in the prints submitted for publication, and in the first proofs received. except that in the latter all the tracks were fainter. However, in Fig. 1 of the published note, the track $F G$ appears much more pronounced and thicker than in the original prints-being quite obvious while other electron tracks in the same region are scarcely detectable. A new set of blocks was made for the final publication; the Editors assure us that no part of Fig. 1 received preferential treatment and suggest that the great intensity of the track concerned may have arisen from a very favourable inclination of its direction with the mesh of the screen used in reproduction.

We take this opportunity of pointing out that the arrow pointing to the $\delta$-track at $E$ in Fig. 4 should be about $2 \mathrm{~mm}$. lower. 